\title{
Arbuscular mycorrhizal symbiosis influences arsenic accumulation and speciation in Medicago truncatula L. in arsenic-contaminated soil
}

\author{
Xin Zhang ${ }^{1}$, Bai-Hui Ren ${ }^{1}$, Song-Lin Wu, Yu-Qing Sun, Ge Lin, Bao-Dong Chen* \\ State Key Laboratory of Urban and Regional Ecology, Research Center for Eco-Environmental Sciences, Chinese Academy of Sciences, Beijing 100085, China
}

\section{H I G H L I G H T S}

- DMA was detected only in shoots of mycorrhizal plants.

- Mycorrhizal inoculation increased the percentage of As(III) in total As in plants.

- AM fungi are potentially involved in As transformation in the plant-soil continuum.

\section{A R T I C L E I N F O}

\section{Article history:}

Received 24 January 2014

Received in revised form 12 June 2014

Accepted 14 June 2014

Available online 11 July 2014

Handling Editor: I. Cousins

\section{Keywords:}

Arbuscular mycorrhizal fungi

Arsenic speciation

Phosphorus

Medicago truncatula

Mutant

\begin{abstract}
A B S T R A C T
In two pot experiments, wild type and a non-mycorrhizal mutant (TR25:3-1) of Medicago truncatula were grown in arsenic (As)-contaminated soil to investigate the influences of arbuscular mycorrhizal fungi (AMF) on As accumulation and speciation in host plants. The results indicated that the plant biomass of M. truncatula was dramatically increased by AM symbiosis. Mycorrhizal colonization significantly increased phosphorus concentrations and decreased As concentrations in plants. Moreover, mycorrhizal colonization generally increased the percentage of arsenite in total As both in shoots and roots, while dimethylarsenic acid (DMA) was only detected in shoots of mycorrhizal plants. The results suggested that AMF are most likely to get involved in the methylating of inorganic As into less toxic organic DMA and also in the reduction of arsenate to arsenite. The study allowed a deeper insight into the As detoxification mechanisms in AM associations. By using the mutant $M$. truncatula, we demonstrated the importance of AMF in plant As tolerance under natural conditions.
\end{abstract}

(C) 2014 Elsevier Ltd. All rights reserved.

\section{Introduction}

Arsenic (As) is ubiquitous in the lithosphere, hydrosphere and biosphere (Cullen and Reimer, 1989), and its wide use in many industries has caused soil contamination worldwide (Smith et al., 1998; Meharg and Hartley-Whitaker, 2002). Excessive As in the soil not only affects plant growth, but also poses a great threat to human health and ecological safety as a consequence of uptake by crops and migration into water (Fitz and Wenzel, 2002; Meharg, 2004).

The environmental chemistry of As is quite complex, and As may present in both inorganic forms such as arsenate $[\mathrm{As}(\mathrm{V})]$ and arsenite $[\mathrm{As}(\mathrm{III})]$, and organic forms such as monomethylarsonic acid (MAA), dimethylarsinic acid (DMA) and other forms in soils and plants (Quaghebeur and Rengel, 2005). Different As species

\footnotetext{
* Corresponding author. Address: No. 18, Shuangqing road, Haidian district, Beijing 100085, China. Tel.: +86 106284 9068; fax: +86 1062923549 .

E-mail address: bdchen@rcees.ac.cn (B.-D. Chen).

1 These authors contributed equally to this work.
}

exhibit different chemo-physical traits and therefore have different mobility, bioavailability and toxicity. Usually soluble inorganic As is more toxic than organic species, and As(III) is more toxic than As(V) (Fitz and Wenzel, 2002; Meharg and Hartley-Whitaker, 2002; Chakrabarty et al., 2009). As(V), as the main As species in aerobic soils, once absorbed, can be rapidly reduced to As(III) (Duan et al., 2005). Detoxification mechanisms of As(III) in plants include efflux from the roots, sequestration in an non-complex form in vacuoles, and transformation into less toxic organic forms (Lombi et al., 2002; Wang et al., 2002; Zhao et al., 2003).

Arbuscular mycorrhizal fungi (AMF), as an important group of soil fungi, can form symbiotic associations with more than $80 \%$ of the land plant families (Schwarzott et al., 2001). AMF can essentially improve plant mineral nutrition and plant water relations ( $\mathrm{Li}$ et al., 2014), and enhance plant resistance to heavy metal contaminations (Hildebrandt et al., 2007). Recent studies show that the arbuscular mycorrhizas naturally occur in As-contaminated soils (Smith et al., 2010) and mycorrhizal inoculation can improve the As tolerance of tomato (Liu et al., 2005b), maize (Bai et al., 2008), 
white clover and ryegrass (Dong et al., 2008), plantain (Orłowska et al., 2012) and Chinese brake fern (Leung et al., 2013). As(V), as the main As species in aerobic environment, behaves similarly as phosphate and is a competitor for the phosphate transporters into plants (Asher and Reay, 1979). As AMF play key roles in plant acquisition of phosphorus (P) (Smith et al., 2003), it is therefore essential to take $\mathrm{P}-\mathrm{As}$ interactions into account for understanding the involvement of AMF in plant uptake of $\mathrm{As}(\mathrm{V})$.

Recent studies have partially uncovered the underlying mechanisms of enhanced plant resistance to As by AM associations. Under As contaminations, AMF could effectively improve plant $\mathrm{P}$ nutrition and growth, resulting in a "dilution effect" on As in plant tissues (Chen et al., 2007; Xia et al., 2007; Xu et al., 2008). More importantly, AMF may also directly mediate As uptake by plants. Gonzalez-Chavez et al. (2002) found that AMF could reduce As(V) influx into excised roots of $H$. lanatus. Christophersen et al. (2009) reported that AM colonization reduced As(V) uptake in barley via down-regulation of the high-affinity Pi transports in plant roots that also absorbed $\mathrm{As}(\mathrm{V})$. As reported by González-Chávez et al. (2011), AMF may also contribute to As exclusion involving reducing $\mathrm{As}(\mathrm{V})$ to $\mathrm{As}(\mathrm{III})$ and pumping $\mathrm{As}(\mathrm{III})$ out of the fungal cells. Moreover, AM symbiosis could alleviate $\mathrm{As}(\mathrm{V})$ toxicity by mitigating oxidative stress (Yu et al., 2009; Garg and Singla, 2012), and influencing the distribution of different As species in plants (Yu et al., 2009; Chen et al., 2012). Ultra Jr et al. (2007) reported the occurrence of less toxic DMA only in the mycorrhizosphere. However, direct evidences are still lacking as for the role of AMF in detoxification of As particularly by influencing As speciation in host plants.

Nevertheless, most previous experiments investigating the interactions of AMF with host plants under As contaminations were performed under sterilized conditions. Such experiments might have neglected the impacts of other soil microorganisms and thus failed to reveal the significance of AM fungi under natural conditions. An experiment under unsterilized condition was conducted by Leung et al. (2010). However, as plants naturally can be colonized by indigenous AM fungi even for the uninoculated control, it was therefore insufficient to evaluate the mycorrhizal involvements in plant As metabolism. Due to the fact that any study on the role of AMF in As detoxification in host plants is ultimately directed to develop mycorrhizal technology for remediation of contaminated soils, it is essential to understand the role of AMF in plant tolerance to As under natural conditions. However such information so far is very limited.

In the present study, two pot experiments were carried out to investigate As speciation and detoxification in host plants as influenced by AMF. In the first experiment, wild type Medicago truncatula inoculated with/without AMF Rhizophagus irregularis was grown in sterilized As-contaminated soil amended with different levels of $\mathrm{P}$, in order to investigate the involvements of AMF in plant As metabolism and the potential influences of P-As interactions on the mycorrhizal functions. In the second experiment, wild type and the non-mycorrhizal mutant TR25:3-1 (Sagan et al., 1995) of $M$. truncatula were grown in unsterilized As-contaminated soil to reveal the role of AMF in alleviation of As phytotoxicity under natural conditions.

\section{Materials and methods}

\subsection{Host plants}

Seeds of medic plants ( $M$. truncatula L., wild type cv. Jemalong A17 and the mutant TR25:3-1) were obtained from the Institute of Subtropical Agriculture, Chinese Academy of Sciences. The seeds were surface sterilized in $10 \%(\mathrm{v} / \mathrm{v}) \mathrm{H}_{2} \mathrm{O}_{2}$ solution for $10 \mathrm{~min}$, then immersed in deionized water for $10 \mathrm{~h}$. They were then pregerminated on moist filter paper for about $48 \mathrm{~h}$ at $27^{\circ} \mathrm{C}$ till emergence of radicles. The seeds were selected for uniformity before sowing.

\subsection{AMF inoculums}

The AM fungus $R$. irregularis Schenck \& Smith (BJ09) was provided by Institute of Plant Nutrition and Resources, Beijing Academy of Agriculture and Forestry. The fungus was propagated in pot culture with maize plants grown in a sandy soil for 10 weeks. Inoculum from pot culture was a mixture of spores, mycelium, sandy soil and root fragments containing approximately 1000 spores per $100 \mathrm{~g}$ soil.

\subsection{Cultivation media}

The experimental soil was collected from an As contaminated site (N25 $\left.35.22^{\prime \prime}, \mathrm{E} 113^{\circ} 00.21^{\prime \prime}\right)$ in Chenzhou City, Hunan Province, China. The soil had a pH value of 7.93 (1:2.5 soil to water), $5.25 \%$ organic matter, extractable $P$ content of $13.00 \mathrm{mg} \mathrm{kg}^{-1}$ (extracted by $0.5 \mathrm{M} \mathrm{NaHCO}_{3}$ following the methods described by Olsen et al., 1954) and extractable As of $4.54 \mathrm{mg} \mathrm{kg}^{-1}$ (extracted by $0.5 \mathrm{M} \mathrm{NaHCO}_{3}$ ). The soil contained $93.53 \mathrm{mg} \mathrm{As} \mathrm{kg}{ }^{-1}, 14.03 \mathrm{mg}$ $\mathrm{Cu} \mathrm{kg}{ }^{-1}, 566.18 \mathrm{mg} \mathrm{Mg} \mathrm{kg}^{-1}, 358.22 \mathrm{mg} \mathrm{Mn} \mathrm{kg}{ }^{-1}$ and $103.18 \mathrm{mg}$ $\mathrm{Zn} \mathrm{kg}{ }^{-1}$. Total metal concentrations were measured by inductively coupled plasma-optical emission spectroscopy (ICP-OES, Perkin Elmer Optima $2000 \mathrm{DV}$ ) following $\mathrm{HNO}_{3}$ - $\mathrm{HF}$ digestion. Before the experiment, the soil was passed through a $2 \mathrm{~mm}$ sieve and received basal nutrients without $\mathrm{P}$ as recommended by Pearson and Jakobsen (1993).

\subsection{Experimental procedure}

In the first experiment, experimental soil was sterilized by r-ray (20 kGy, $10 \mathrm{MeV}$ electron beam) before use. Round plastic pots that can accommodate $1 \mathrm{~kg}$ soil were used for cultivation of test plants, the wild type of $M$. truncatula. Three P addition levels (0, 20 and $60 \mathrm{mg} \mathrm{kg}^{-1}$ ) were arranged with appropriate amount of analytical grade $\mathrm{KH}_{2} \mathrm{PO}_{4}$ solution thoroughly mixed into the soil. Mycorrhizal treatments received $50 \mathrm{~g}$ of the fungal inoculum, which was also carefully mixed into the growth medium. Non-mycorrhizal treatments received an equivalent amount of autoclaved soil-sand mixture together with a filtrate (by using slow speed quantitative filter paper) of the fungal inoculum to provide a similar microflora except for the absence of the mycorrhizal fungus. There were two inoculation treatments in combination with three $\mathrm{P}$ addition levels, resulting in a total of 6 treatments. Each treatment has four replicates giving a total of 24 pots in a two-factor completely random design.

In the second experiment, wild type and the non-mycorrhizal mutant (which cannot be colonized by AM fungi) of M. truncatula were grown in unsterilized soil in same pots with the first experiment. There were two treatments and five replicates each, giving a total of 10 pots.

Ten pre-germinated seeds were sown in each pot and thinned to five one week after seedling emergence. The experiment was conducted in a controlled environment chamber with $16 \mathrm{~h} /$ $25^{\circ} \mathrm{C}$ day, $8 \mathrm{~h} / 18^{\circ} \mathrm{C}$ night, and a light intensity of $700 \mu \mathrm{mol} \mathrm{m}{ }^{-2}$ $\mathrm{s}^{-1}$ provided by supplementary illumination. The plants grew for 16 weeks from 14 November 2012 to 5 March 2013. During the experimental period, de-ionized water was added as required to maintain soil moisture content of c.a. $55 \%$ water holding capacity by regular weighing. 


\subsection{Harvest and chemical analysis}

Plant shoots and roots were harvested separately. Root samples were first carefully washed with tap water to remove adhering soil particles and rinsed in ice-cold phosphate solution containing $1.0 \mathrm{mM} \mathrm{K}_{2} \mathrm{HPO}_{4}, 5.0 \mathrm{mM}$ MES and $0.5 \mathrm{mM} \mathrm{Ca}\left(\mathrm{NO}_{3}\right)_{2}$ for $10 \mathrm{~min}$ to remove As in the apoplast of the roots (Abedin et al., 2002). Roots and shoots were then carefully washed with de-ionized water, blotted dry and weighed. Sub-samples of fresh roots were collected for the determination of AM colonization. The rest samples were frozen in liquid nitrogen and dry weights were recorded after freeze-dried for $72 \mathrm{~h}$.

Sub-samples of fresh roots were cleared in $10 \% \mathrm{KOH}$ and stained with Trypan blue following a modification procedure of Phillips and Hayman (1970) by omitting phenol from solutions and $\mathrm{HCl}$ from the rinse. Percentage root colonization and root length were determined by the grid-intersect method (Giovanetti and Mosse, 1980).

Approximately $0.2 \mathrm{~g}$ freeze-dried samples were weighed and digested by $10 \mathrm{~mL} \mathrm{HNO}_{3}$ using a microwave accelerated reduction system (Mars 5, CEM Co., Ltd., USA). The dissolved samples were analyzed for P by ICP-OES and for As by inductively coupled plasma-mass spectroscopy (ICP-MS) (Agilent7500, Agilent Technology, USA).

For analysis of As speciation in plants, the freeze-dried plant samples were extracted with $10 \mathrm{~mL}$ of $1 \%$ nitric acid in the microwave accelerated reaction system. The extracted solutions were filtered and passed through a $0.45 \mu \mathrm{m}$ nylon filter. Samples were kept on ice in the dark and analyzed soon after extraction in order to minimize potential transformation of As species. Different As species in the extracts was determined by high performance liquid chromatography-inductively coupled plasma-mass spectrometry (HPLC-ICP-MS) (Agilent 7500, Agilent Technology, USA). Chromatographic columns consisted of a Hamilton precolumn (11.2 mm, 12-20 mm) and a Hamilton PRP-X100 10- $\mu \mathrm{m}$ anionexchange column $(240 \times 4.1 \mathrm{~mm})$. The mobile phase consisted of $10 \mathrm{mM} \mathrm{NH}_{4} \mathrm{H}_{2} \mathrm{PO}_{4}$ and $\mathrm{NH}_{4} \mathrm{NO}_{3}$, adjusted to $\mathrm{pH} 6.2$ using ammonia. Arsenic species was verified by the coincidence of retention times with those of the standards including $\mathrm{As}(\mathrm{III}), \mathrm{As}(\mathrm{V})$, DMA and MMA, and quantified by external calibration curves with peak areas.

\subsection{Data analysis}

Data from the first experiment were subjected to two-way ANOVA to examine significance of mycorrhizal inoculation and $P$ application, except that data of root colonization from inoculated treatments were subjected to one-way ANOVA to test the effects of $P$ application. Data from the second experiment were analyzed by T-test to compare differences in assayed variables between wild type and mutant. All data analysis was performed using windowsbased SPSS 13.0 software package.

\section{Results}

\subsection{Experiment 1}

Mycorrhizal colonization on inoculated plants decreased significantly with increasing $\mathrm{P}$ addition levels $(P<0.01)$. Colonization rates of $66 \%, 55 \%$ and $51 \%$ were recorded under $P$ addition level of 0,20 and $60 \mathrm{mg} \mathrm{kg}^{-1}$ respectively. No mycorrhizal colonization was detected in the uninoculated plants.

Plant growth was markedly improved by mycorrhizal colonization at all $P$ addition levels $(P<0.001)$. Symptoms of As phytotoxicity (necrosis of leaves) were also observed in non-inoculated plants which showed poor growth and could hardly survive the
As contamination especially under non-P amendments. Both shoot and root dry weights were interactively affected by mycorrhizal colonization and $\mathrm{P}$ additions $(P<0.05)$. $\mathrm{P}$ addition to the soil increased the plant dry weights of uninoculated plants but not that of inoculated plants (Fig. 1).

Similarly, under all P addition levels, mycorrhizal colonization significantly increased both shoot and root $\mathrm{P}$ concentrations $(P<0.001$, Fig. 2$)$. Shoot $P$ concentration increased with $P$ addition only for uninoculated plants, indicating a significant interaction $(P<0.01)$ of mycorrhizal inoculation with $P$ addition. Compared to uninoculated controls, shoot and root As concentrations were significantly lower in inoculated plants $(P<0.001)$, while $P$ addition made no difference to plant As concentrations (Fig. 3).

Shoot to root ratio $(S / R)$ of both $P$ and As uptake tended to be higher in mycorrhizal plants under $P$ addition level of 0 and $20 \mathrm{mg} \mathrm{kg}^{-1}$. However, the S/R of P uptake was lower for inoculated plants, and no difference in $S / R$ of As uptake were found between inoculation treatments under $\mathrm{P}$ addition level of $60 \mathrm{mg} \mathrm{kg}^{-1}$ (Table 1).

Generally the inorganic As(III) and As(V) were the dominant As species in all plant samples, while small amounts of DMA were detected in shoots of mycorrhizal plants only (Fig. 4). The percentage of $\mathrm{As}(\mathrm{III})$ in the total As showed a remarkable increase in mycorrhizal plants compared with corresponding uninoculated plants under $P$ additional level of 0 and $20 \mathrm{mg} \mathrm{kg}^{-1}$. Besides, the percentage of $\mathrm{As}$ (III) was dramatically higher in the shoots than in the roots irrespective to P addition levels (Fig. S1).
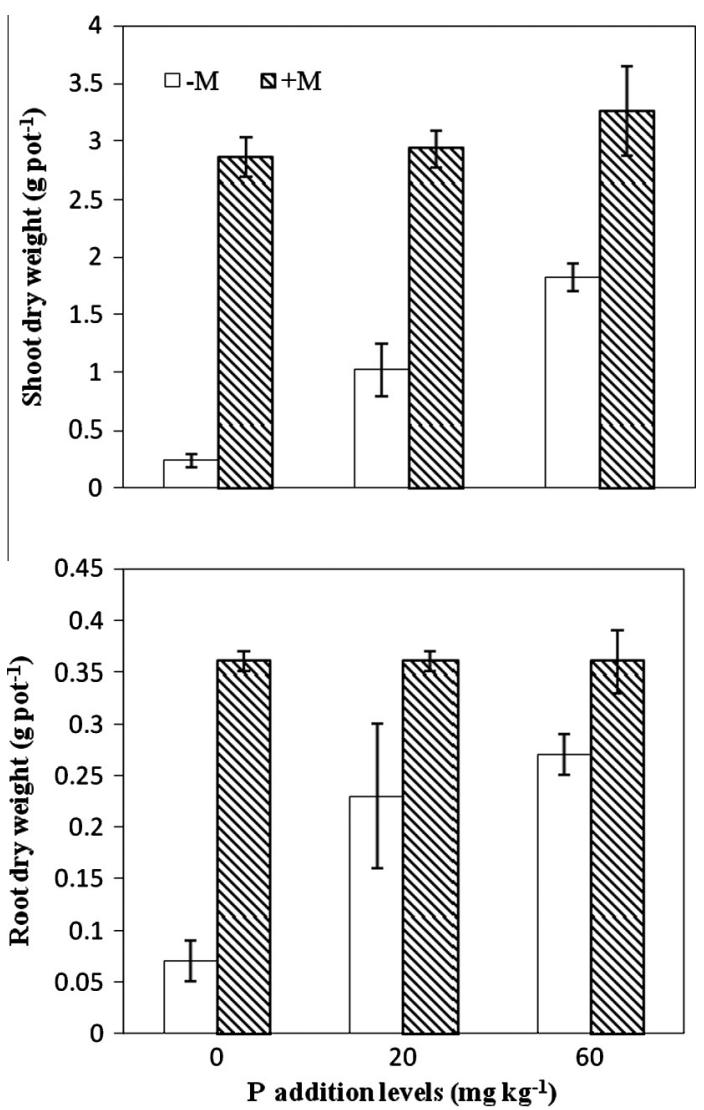

Fig. 1. Shoot and root dry weights of M. truncatula inoculated with/without $R$ irregularis grown in an arsenic contaminated soil under different $\mathrm{P}$ addition levels (mean $\pm \mathrm{SE}, n=4)$. $-\mathrm{M}$ and $+\mathrm{M}$ represent uninoculated and inoculated treatments respectively. By analysis of variance, inoculation was highly significant $(P<0.001)$ for both shoot and root; $P$ addition was significant for shoot $(P<0.01)$ and root $(P<0.05)$; Interaction of inoculation with $P$ addition was significant $(P<0.05)$ for both shoot and root. 

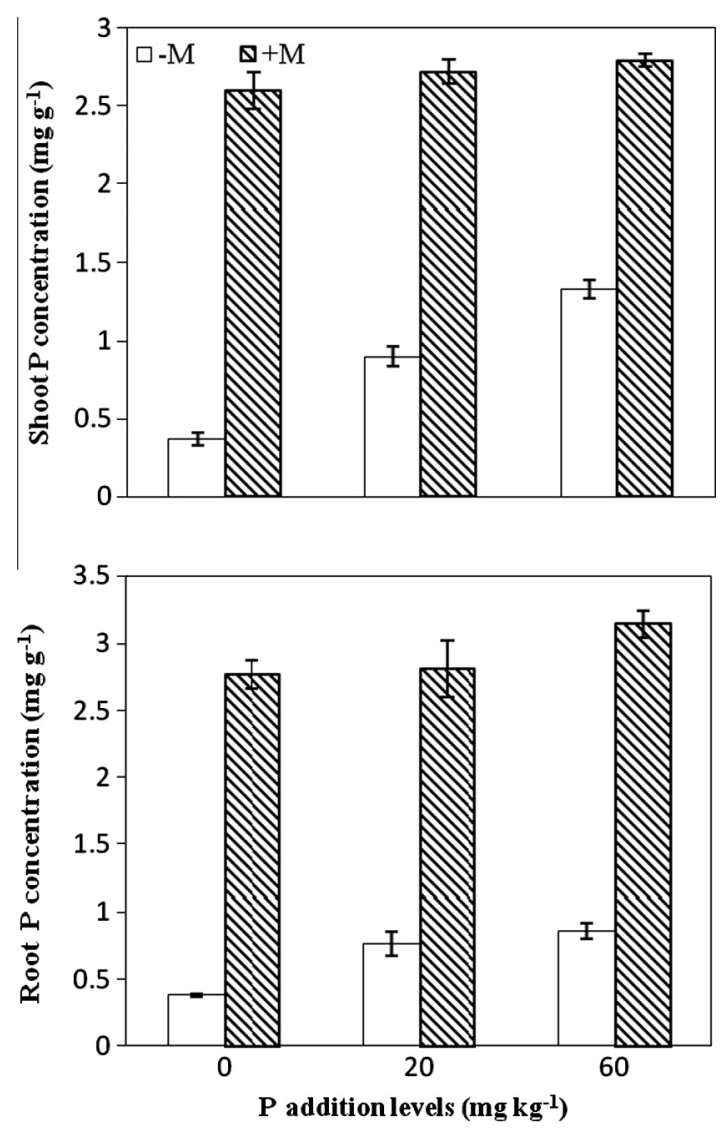

Fig. 2. Shoot and root $\mathrm{P}$ concentrations of $M$. truncatula inoculated with/without $R$. irregularis grown in an arsenic contaminated soil under different $\mathrm{P}$ addition levels (mean $\pm \mathrm{SE}, n=4)$. $-\mathrm{M}$ and $+\mathrm{M}$ represent uninoculated and inoculated treatments respectively. By analysis of variance, inoculation was highly significant $(P<0.001)$ for both shoot and root; $P$ addition was significant for shoot $(P<0.001)$ and root $(P<0.05)$; Interaction of inoculation with $P$ addition was only highly significant $(P<0.001)$ for shoot.

\subsection{Experiment 2}

No root colonization was observed in the mutant $M$. truncatula, whereas the wild type plants had $57 \%$ of root length colonized by AMF. The biomass as well as P concentrations in both shoots and roots of the wild type $M$. truncatula were significantly higher than those of the mutant $(P<0.001)$. On the other side, As concentrations in shoots $(P<0.001)$ and roots $(P<0.05)$ tended to be lower in the wild type. Moreover, the wild type exhibited higher $S / R$ of both $\mathrm{P}(P<0.001)$ and As $(P<0.01)$ uptake (Table 2$)$. Typical symptoms of As phytotoxicity were also observed in the mutant $M$. truncatula.

Small amounts of DMA were found only in the shoots of wild type plants. $\mathrm{As}(\mathrm{V})$ and $\mathrm{As}(\mathrm{III})$ concentrations were consistently lower in shoots and roots of the wild type compared with the mutant (Fig. 5). However, the percentage of As(III) in the total As tended to be higher in the wild type (Fig. S2).

\section{Discussion}

In the present study, two pot experiments were performed to investigate the influences of AMF on As accumulation and speciation in host plants. The first experiment aimed to reveal the potential role of AMF in alleviation of As phytotoxicity by growing wild type $M$. truncatula in association with AM fungus in sterilized Ascontaminated soil, while the second experiment aimed to further confirm AMF functions under natural conditions by growing wild
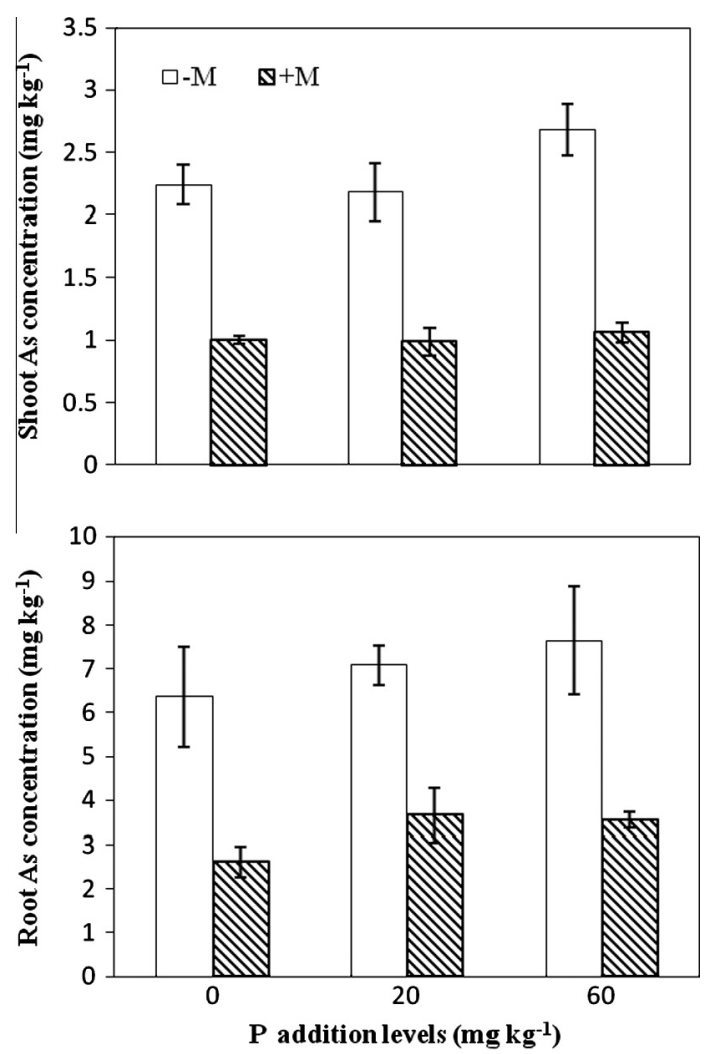

Fig. 3. Shoot and root As concentrations of $M$. truncatula inoculated with/without $R$. irregularis grown in an arsenic contaminated soil under different $\mathrm{P}$ addition levels (mean $\pm \mathrm{SE}, n=4$ ). $-\mathrm{M}$ and $+\mathrm{M}$ represent uninoculated and inoculated treatments respectively. By analysis of variance, only inoculation was highly significant $(P<0.001)$ for both shoot and root.

type and the mycorrhizal mutant (TR25:3-1) of M. truncatula in unsterilized As-contaminated soil.

A key finding from the present study was that AM inoculation could alleviate As phytotoxicity potentially by influencing As speciation and transformation in host plants. It was most interesting that DMA was only found in shoots of mycorrhizal plants (Figs. 4 and 5). As suggested by Lomax et al. (2012), methylated As species in plants could only originate from soil microorganisms. Plants are unable to methylate inorganic As, but instead take up methylated As. Arsenic methylation has been well demonstrated in a wide range of bacteria, fungi, yeasts and algae (Fitz and Wenzel, 2002). Considering that DMA was only found in mycorrhizal plants and in the mycorrhizosphere soil (Ultra Jr et al., 2007), we could propose that AMF are possibly involved in methylating inorganic As into less toxic DMA. Once transformed into DMA, arsenic could be quickly transported to plant shoots (Jia et al., 2012). In the study of Jia et al. (2012), methylated As species were detected in plant roots, whereas the DMA concentrations were much lower in roots than in shoots. However, by the reading of HPLC-ICP-MS, we failed to detect DMA in all root samples, meanwhile only small amounts of DMA were detected in the shoots of mycorrhizal plants. We could only suspect that the methylated As concentrations in roots might be too low to be detected in our study.

Despite all, As transformation by AMF could potentially serve as an important mechanism underlying the plant detoxification of As. However, it should be noted that based on the present study we could hardly conclude whether AMF directly contribute to As methylation, as an indirect mechanism might be associated with the interactions of AMF with other soil microorganisms. Although the soil used in the first experiment was initially sterilized, the experiment was conducted in open air and soil microbes could 
Table 1

Shoot to root ratio of $\mathrm{P}$ and As content of $M$. truncatula inoculated with/without $R$. irregularis grown in an arsenic contaminated soil under different $\mathrm{P}$ addition levels.

\begin{tabular}{|c|c|c|c|c|}
\hline \multirow[t]{2}{*}{$\mathrm{P}$ addition levels $\left(\mathrm{mg} \mathrm{kg}^{-1}\right)$} & \multicolumn{2}{|c|}{ Shoot/root ratio of P content } & \multicolumn{2}{|c|}{ Shoot/root ratio of As content } \\
\hline & $-\mathrm{M}^{\mathrm{b}}$ & $+\mathrm{M}$ & $-\mathrm{M}$ & $+\mathrm{M}$ \\
\hline 0 & $3.84 \pm 0.62^{\mathrm{a}}$ & $7.51 \pm 0.24$ & $1.09 \pm 0.02$ & $3.3 \pm 0.57$ \\
\hline 20 & $5.63 \pm 0.77$ & $7.96 \pm 0.53$ & $1.4 \pm 0.11$ & $2.54 \pm 0.68$ \\
\hline 60 & $10.49 \pm 0.72$ & $7.87 \pm 0.44$ & $2.68 \pm 0.71$ & $2.64 \pm 0.15$ \\
\hline Significance of ${ }^{c}$ & & & & \\
\hline Inoculation & ${ }^{*}$ & * & & \\
\hline$P$ addition & $* * *$ & ns & & \\
\hline Interaction & $* * *$ & ns & & \\
\hline
\end{tabular}

ns, Not significant.

a Data are presented as mean values \pm SE $(n=4)$.

b $-\mathrm{M}$ and $+\mathrm{M}$ represent uninoculated and inoculated treatments respectively.

c By two-way ANOVA.

*** $P<0.001$.

${ }^{*} P<0.05$
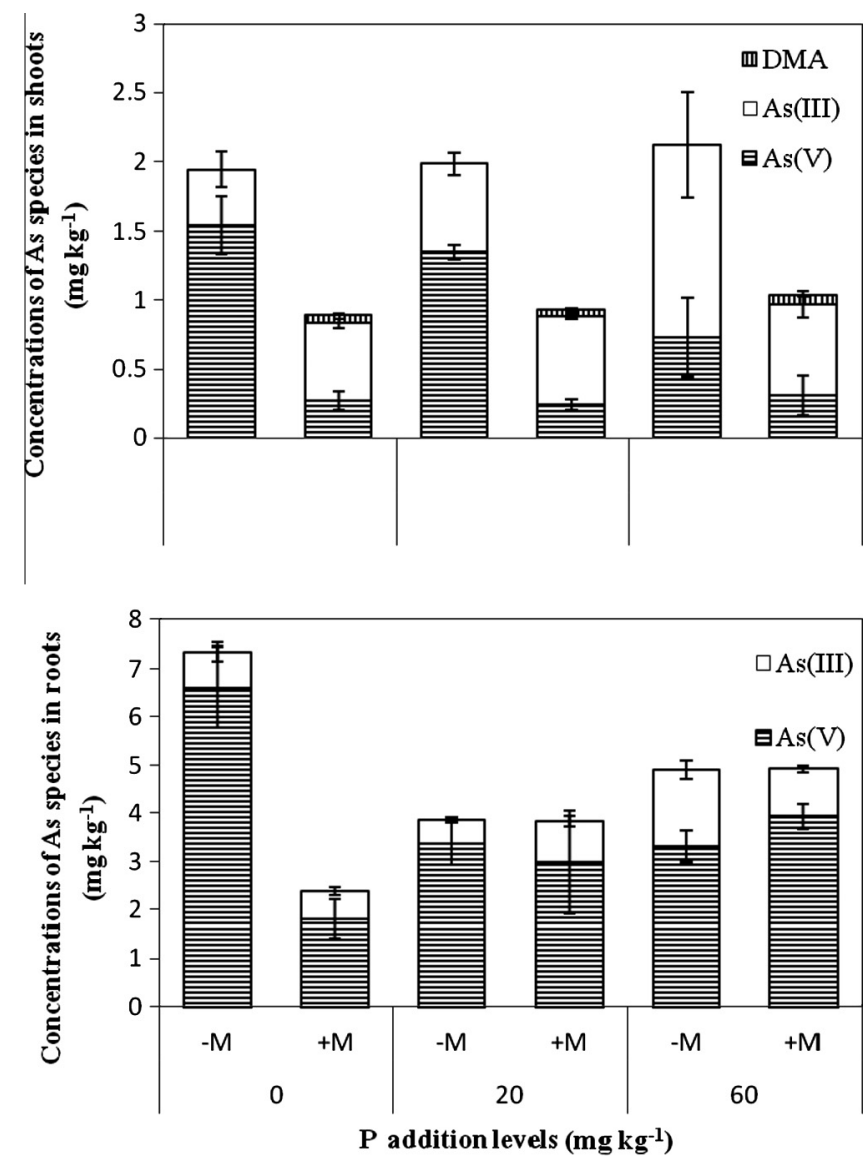

Fig. 4. As speciation in $M$. truncatula inoculated with/without $R$. irregularis grown in an arsenic contaminated soil under different P addition levels (mean $\pm \mathrm{SE}, n=3$ ). $-\mathrm{M}$ and $+\mathrm{M}$ represent uninoculated and inoculated treatments respectively.

potentially be reintroduced. Besides, mycorrhizal roots might release organic substrates which could activate the microorganisms and serve as methyl donors for bio-methylation by microorganisms (Mukhopadhyay et al., 2002). Obviously, further work to identify the As methyltransferase genes in AMF should be conducted in order to provide the direct evidence for As methylation by AMF.

Another important finding from the experiments was that the percentage of $\mathrm{As}$ (III) in the total As tended to be higher in mycorrhizal plants especially under low P supply (Fig. S1 and S2). In microorganisms and plants, $\operatorname{As}(\mathrm{V})$ is metabolized and detoxified by reduction to $\mathrm{As}(\mathrm{III})$, and the latter is subsequently subjected to complexation with thiol compounds, storage in vacuoles or efflux into the environment (Meharg and Hartley-Whitaker, 2002; Rosen, 2002; Duan et al., 2007). Moreover, As(V) reduction and subsequent methylation are crucial steps in the biotransformation of inorganic arsenic (Duan et al., 2007). The increased proportion of $\mathrm{As}(\mathrm{III})$ due to mycorrhizal colonization indicated that AMF could play an important role in the reduction of $\mathrm{As}(\mathrm{V})$ to As(III), and thereby alleviating As toxicity in host plants. However, direct evidences for $\mathrm{As}(\mathrm{V})$ reduction by $\mathrm{AM}$ fungi are still unavailable.

The use of TR25:3-1, the non-mycorrhizal mutant of M. trunctu$l a$, in the second experiment provided further support to the ecological significance of mycorrhizal symbiosis in plant adaptation to As contaminated environments. Previous experiments performed under sterilized conditions or unsterilized conditions might inevitably have exaggerated the importance of AMF in As detoxification in plants, as most experiments failed to authentically reflect the natural situations. By growing wild type and the mutant (TR25:3-1) of M. truncatula in unsterilized As-contaminated soil, we were able to evaluate the importance of indigenous AMF in plant performance without disturbance of soil microbial communities. All in all, compared with the mutant, the wild type $M$. truncatula exhibited higher plant dry weights, P concentrations and proportion of $\mathrm{As}(\mathrm{III})$, but lower As concentrations, suggesting that AM fungi do play an important role in alleviation of As phytotoxicity under natural conditions.

The importance of improved P nutrition in the protective effects of mycorrhizal association on host plants against As contaminations has also been observed in our study, which is in accordance with many previous studies (Chen et al., 2007; Xia et al., 2007; Xu et al., 2008). As been well documented, the improvement of plant P nutrition would directly lead to better plant growth and so-called "dilution effects" on As in plant tissues. Moreover, the effects of AM fungi on plant $P$ acquisition and growth were much obvious under lower P addition levels (Figs. 1 and 2). It's well known that plants could regulate the development of mycorrhizal symbiosis depending on the P availability. Host plants might rely more on AMF for P acquisition under low P supply. Though the experimental results showed that $\mathrm{P}$ addition to soil did not influence As accumulation in plants, plant $P$ nutrition status would still indirectly affect As accumulation by influencing plant growth and the mycorrhizal development. Furthermore, it should be noted that $P$ deficiency could be one of the important reasons for the plant growth depression, while As contamination may also be involved, as symptoms of As phytotoxicity (necrosis of leaves) were observed in non-mycorrhizal plants. As we used naturally 
Table 2

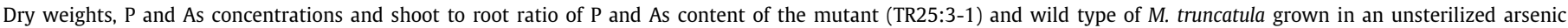
contaminated soil.

\begin{tabular}{|c|c|c|c|c|c|c|c|c|}
\hline & \multicolumn{2}{|l|}{$\mathrm{DW}\left(\mathrm{g} \mathrm{pot}^{-1}\right)$} & \multicolumn{2}{|c|}{$\mathrm{P}$ conc. $\left(\mathrm{mg} \mathrm{kg}^{-1}\right)$} & \multicolumn{2}{|c|}{ As conc. (mg kg-1) } & \multirow[t]{2}{*}{ Shoot/root ratio of $\mathrm{P}$ content } & \multirow[t]{2}{*}{ Shoot/root ratio of As content } \\
\hline & Shoots & Roots & Shoots & Roots & Shoots & Roots & & \\
\hline Mutant & $0.15 \pm 0.01^{\mathrm{a}}$ & $0.07 \pm 0.003$ & $0.4 \pm 0.03$ & $0.8 \pm 0.05$ & $1.27 \pm 0.05$ & $6.92 \pm 1.11$ & $1.15 \pm 0.16$ & $0.44 \pm 0.05$ \\
\hline Wild type & $3.55 \pm 0.16$ & $0.42 \pm 0.02$ & $2.22 \pm 0.03$ & $2.61 \pm 0.11$ & $0.65 \pm 0.05$ & $3.63 \pm 0.24$ & $7.31 \pm 0.42$ & $1.57 \pm 0.22$ \\
\hline Significance $^{\mathrm{b}}$ & & & & & & & & \\
\hline
\end{tabular}

a Data are presented as mean values \pm SE $(n=5)$

b By T-test.

*** $P<0.001$

* $P<0.05$.

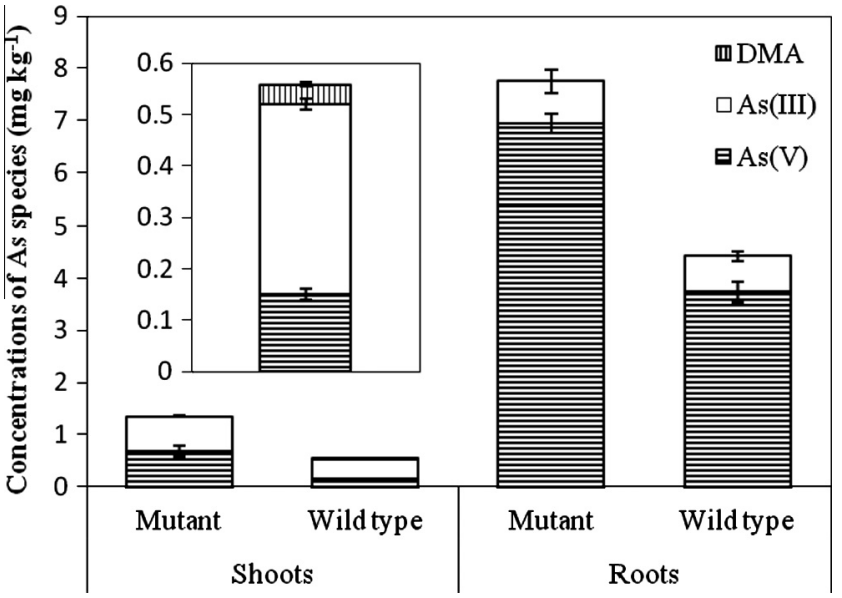

Fig. 5. As speciation in the non-mycorrhizal mutant (TR25:3-1) and wild type of $M$. truncatula grown in an unsterilized arsenic contaminated soil (mean $\pm \mathrm{SE}, n=3$ ). Arsenic speciation in shoots of wild type $M$. truncatula was shown in a small figure with reduced scale of $Y$-axis.

contaminated soil and could not include uncontaminated soil as control, therefore we can hardly evaluate the potential involvements of As contamination in plant response to P additions.

Additionally, our study also showed that mycorrhizal colonization stimulated the transfer of $P$ and As to shoots under low P addition (Tables 1 and 2). Photosynthesis could be stimulated by improved shoot $\mathrm{P}$ nutrition and subsequently lead to better shoot growth. This could be another possible mechanism underlying AMF improvement of plant As tolerance (Dong et al., 2008). Inoculation with AMF could result in higher As accumulation in plant shoots as confirmed by previous studies (Liu et al., 2005a; Orłowska et al., 2012). More As partitioning to shoots seems to be a potential advantage of AMF assisted phytoextraction of As contaminated soils. It should be noted that some studies reported decreased As transfer from roots to shoots in alfalfa (Chen et al., 2007), white clove and ryegrass (Dong et al., 2008). The differences could largely be explained by different plant species and their physiological traits.

\section{Conclusions}

This study demonstrated that AM fungi could enhance As tolerance of $M$. truncatula by improving plant $\mathrm{P}$ nutrition and influencing As accumulation and speciation. The most important finding from this study was that AMF potentially played an important role in the reduction of $\mathrm{As}(\mathrm{V})$ to $\mathrm{As}(\mathrm{III})$ and also methylation of inorganic As into less toxic organic DMA. Furthermore, the use of non-mycorrhizal mutant of $M$. truncatula demonstrated the ecological importance of AMF in plant tolerance to As under natural conditions. The study allowed a deeper insight into the As detoxification mechanisms in mycorrhizal plants, and also supported the potential use of AMF for bioremediation of As contaminated soils. However, further research is still necessary to provide direct evidences for the involvements of AMF in As metabolism in plants.

\section{Acknowledgements}

This study was financially supported by National Natural Science Foundation of China (41101246), International Foundation for Science, Stockholm, Sweden, through a Grant to Xin Zhang (NO. C/4973-1) and National Key Technology R\&D Program, China (2012BAC25B03).

\section{Appendix A. Supplementary material}

Supplementary data associated with this article can be found, in the online version, at http://dx.doi.org/10.1016/j.chemosphere. 2014.06.042.

\section{References}

Abedin, M.J., Feldmann, J., Meharg, A.A., 2002. Uptake kinetics of arsenic species in rice plants. Plant Physiol. 128, 1120-1128.

Asher, C.J., Reay, P.F., 1979. Arsenic uptake by barley seedlings. Funct. Plant Biol. 6, 459-466.

Bai, J.F., Lin, X.G., Yin, R., Zhang, H.Y., Wang, J.H., Chen, X.M., Luo, Y.M., 2008. The influence of arbuscular mycorrhizal fungi on As and P uptake by maize (Zea mays L.) from As-contaminated soils. Appl. Soil Ecol. 38, 137-145.

Chakrabarty, D., Trivedi, P.K., Misra, P., Tiwari, M., Shri, M., Shukla, D., Kumar, S., Rai, A., Pandey, A., Nigam, D., Tripathi, R.D., Tuli, R., 2009. Comparative transcriptome analysis of arsenate and arsenite stresses in rice seedlings. Chemosphere 74, 688-702.

Chen, B.D., Xiao, X.Y., Zhu, Y.G., Smith, F.A., Xie, Z.M., Smith, S.E., 2007. The arbuscular mycorrhizal fungus Glomus mosseae gives contradictory effects on phosphorus and arsenic acquisition by Medicago sativa Linn. Sci. Total Environ. 379, 226-234.

Chen, X., Li, H., Chan, W.F., Wu, C., Wu, F., Wu, S., Wong, M.H., 2012. Arsenite transporters expression in rice (Oryza sativa L.) associated with arbuscular mycorrhizal fungi (AMF) colonization under different levels of arsenite stress. Chemosphere 89, 1248-1254.

Christophersen, H.M., Smith, F.A., Smith, S.E., 2009. Arbuscular mycorrhizal colonization reduces arsenate uptake in barley via downregulation of transporters in the direct epidermal phosphate uptake pathway. New Phytol. 184, 962-974

Cullen, W.R., Reimer, K.J., 1989. Arsenic speciation in the environment. Chem. Rev. $89,713-764$.

Dong, Y., Zhu, Y.G., Smith, F.A., Wang, Y., Chen, B.D., 2008. Arbuscular mycorrhiza enhanced arsenic resistance of both white clover (Trifolium repens Linn.) and ryegrass (Lolium perenne L.) plants in an arsenic-contaminated soil. Environ. Pollut. 155, 174-181.

Duan, G.L., Zhu, Y.G., Tong, Y.P., Cai, C., Kneer, R., 2005. Characterization of arsenate reductase in the extract of roots and fronds of Chinese brake fern, an arsenic hyperaccumulator. Plant Physiol. 138, 461-469.

Duan, G.L., Zhou, Y., Tong, Y.P., Mukhopadhyay, R., Rosen, B.P., Zhu, Y.G., 2007. A CDC25 homologue from rice functions as an arsenate reductase. New Phytol. $174,311-321$

Fitz, W.J., Wenzel, W.W., 2002. Arsenic transformations in the soil-rhizosphereplant system: fundamentals and potential application to phytoremediation. J. Biotechnol. 99, 259-278. 
Garg, N., Singla, P., 2012. The role of Glomus mosseae on key physiological and biochemical parameters of pea plants grown in arsenic contaminated soil. Sci. Hortic. 143, 92-101.

Giovanetti, M., Mosse, B., 1980. An evaluation of techniques for measuring vesicular arbuscular mycorrhizal infection in roots. New Phytol. 84, 489-500.

González-Chávez, M.d.C.A., Ortega-Larrocea, M.d.P., Carrillo-González, R., LópezMeyer, M., Xoconostle-Cázares, B., Gomez, S.K., Harrison, M.J., Figueroa-López, A.M., Maldonado-Mendoza, I.E., 2011. Arsenate induces the expression of fungal genes involved in As transport in arbuscular mycorrhiza. Fungal Biol. 115, 1197-1209.

Gonzalez-Chavez, C., Harris, P.J., Dodd, J., Meharg, A.A., 2002. Arbuscular mycorrhizal fungi confer enhanced arsenate resistance on Holcus lanatus. New Phytol. 155, 163-171.

Hildebrandt, U., Regvar, M., Bothe, H., 2007. Arbuscular mycorrhiza and heavy metal tolerance. Phytochemistry 68, 139-146.

Jia, Y., Huang, H., Sun, G.X., Zhao, F.J., Zhu, Y.G., 2012. Pathways and relative contributions to arsenic volatilization from rice plants and paddy soil. Environ. Sci. Technol. 46, 8090-8096.

Leung, H.M., Leung, A.O., Ye, Z.H., Cheung, K.C., Yung, K.K., 2013. Mixed arbuscular mycorrhizal (AM) fungal application to improve growth and arsenic accumulation of Pteris vittata (As hyperaccumulator) grown in Ascontaminated soil. Chemosphere 92, 1367-1374.

Leung, H.M., Wu, F.Y., Cheung, K.C., Ye, Z.H., Wong, M.H., 2010. Synergistic effects of arbuscular mycorrhizal fungi and phosphate rock on heavy metal uptake and accumulation by an arsenic hyperaccumulator. J. Hazard. Mater. 181, 497-507.

Li, T., Lin, G., Zhang, X., Chen, Y.L., Zhang, S.B., Chen, B.D., 2014. Relative importance of an arbuscular mycorrhizal fungus (Rhizophagus intraradices) and root hairs in plant drought tolerance. Mycorrhiza. http://dx.doi.org/10.1007/s00572-014-0578-3.

Liu, Y., Zhu, Y.G., Chen, B.D., Christie, P., Li, X.L., 2005a. Influence of the arbuscular mycorrhizal fungus Glomus mosseae on uptake of arsenate by the As hyperaccumulator fern Pteris vittata L. Mycorrhiza 15, 187-192.

Liu, Y., Zhu, Y.G., Chen, B.D., Christie, P., Li, X.L., 2005b. Yield and arsenate uptake of arbuscular mycorrhizal tomato colonized by Glomus mosseae BEG167 in As spiked soil under glasshouse conditions. Environ. Int. 31, 867-873.

Lomax, C., Liu, W.J., Wu, L., Xue, K., Xiong, J., Zhou, J., McGrath, S.P., Meharg, A.A., Miller, A.J., Zhao, F.J., 2012. Methylated arsenic species in plants originate from soil microorganisms. New Phytol. 193, 665-672.

Lombi, E., Zhao, F.J., Fuhrmann, M., Ma, L.Q., McGrath, S.P., 2002. Arsenic distribution and speciation in the fronds of the hyperaccumulator Pteris vittata. New Phytol. 156, 195-203.

Meharg, A.A., 2004. Arsenic in rice-understanding a new disaster for South-East Asia. Trends Plant Sci. 9, 415-417.

Meharg, A.A., Hartley-Whitaker, J., 2002. Arsenic uptake and metabolism in arsenic resistant and nonresistant plant species. New Phytol. 154, 29-43.

Mukhopadhyay, R., Rosen, B.P., Phung, L.T., Silver, S., 2002. Microbial arsenic: from geocycles to genes and enzymes. FEMS Microbiol. Rev. 26, 311-325.

Olsen, S.R., Cole, C.V., Watanabe, F.S., Dean, L.A., 1954. Estimation of available phosphorus in soils by extraction with sodium bicarbonate. USDA Circ. 939, 1-19.
Orłowska, E., Godzik, B., Turnau, K., 2012. Effect of different arbuscular mycorrhizal fungal isolates on growth and arsenic accumulation in Plantago lanceolata L. Environ. Pollut. 168, 121-130.

Pearson, J.N., Jakobsen, I., 1993. The relative contribution of hyphae and roots to phosphorus uptake by arbuscular mycorrhizal plants, measured by dual labelling with ${ }^{32} \mathrm{P}$ and ${ }^{33} \mathrm{P}$. New Phytol. 124, 489-494.

Phillips, J.M., Hayman, D.S., 1970. Improved procedures for clearing roots and staining parasitic and vesicular-arbuscular mycorrhizal fungi for rapid assessment of infection. T. Brit. Mycol. Soc. 55, 158-161.

Quaghebeur, M., Rengel, Z., 2005. Arsenic speciation governs arsenic uptake and transport in terrestrial plants. Microchim. Acta 151, 141-152.

Rosen, B.P., 2002. Transport and detoxification systems for transition metals, heavy metals and metalloids in eukaryotic and prokaryotic microbes. Comp. Biochem. Phys. A 133, 689-693.

Sagan, M., Morandi, D., Tarenghi, E., Duc, G., 1995. Selection of nodulation and mycorrhizal mutants in the model plant Medicago truncatula (Gaertn.) after $\gamma$-ray mutagenesis. Plant Sci. 111, 63-71.

Schwarzott, D., Walker, C., Schüßler, A., 2001. Glomus, the largest genus of the arbuscular mycorrhizal fungi (Glomales), is nonmonophyletic. Mol. Phylogenet. Evol. 21, 190-197.

Smith, E., Naidu, R., Alston, A.M., 1998. Arsenic in the soil environment: a review. Adv. Agron. 64, 149-195.

Smith, S.E., Christophersen, H.M., Pope, S., Smith, F.A., 2010. Arsenic uptake and toxicity in plants: integrating mycorrhizal influences. Plant Soil 327, 1-21.

Smith, S.E., Smith, F.A., Jakobsen, I., 2003. Mycorrhizal fungi can dominate phosphate supply to plants irrespective of growth responses. Plant Physiol. $133,16-20$.

Ultra Jr, V.U., Tanaka, S., Sakurai, K., Iwasaki, K., 2007. Effects of arbuscular mycorrhiza and phosphorus application on arsenic toxicity in sunflower (Helianthus annuus L.) and on the transformation of arsenic in the rhizosphere. Plant Soil 290, 29-41.

Wang, J., Zhao, F.J., Meharg, A.A., Raab, A., Feldmann, J., McGrath, S.P., 2002. Mechanisms of arsenic hyperaccumulation in Pteris vittata. Uptake kinetics, interactions with phosphate, and arsenic speciation. Plant Physiol. 130, 1552 1561.

Xia, Y.S., Chen, B.D., Christie, P., Smith, F.A., Wang, Y.S., Li, X.L., 2007. Arsenic uptake by arbuscular mycorrhizal maize (Zea mays L.) grown in an arseniccontaminated soil with added phosphorus. J. Environ. Sci. 19, 1245-1251.

Xu, P.L., Christie, P., Liu, Y., Zhang, J., Li, X.L., 2008. The arbuscular mycorrhiza fungus Glomus mosseae can enhance arsenic tolerance in Medicago truncatula by increasing plant phosphorus status and restricting arsenate uptake. Environ. Pollut. 156, 215-220.

Yu, Y., Zhang, S.Z., Huang, H.L., Luo, L., Wen, B., 2009. Arsenic accumulation and speciation in maize as affected by inoculation with arbuscular mycorrhizal fungus Glomus mosseae. J. Agric. Food Chem. 57, 3695-3701.

Zhao, F.J., Wang, J.R., Barker, J.H.A., Schat, H., Bleeker, P.M., McGrath, S.P., 2003. The role of phytochelatins in arsenic tolerance in the hyperaccumulator Pteris vittata. New Phytol. 159, 403-410. 